\title{
Immune mechanisms of ischemia-reperfusion injury in transplantation
}

\author{
Saami Khalifian, Justin M. Broyles, Sami H. Tuffaha, Mohammed Alrakan, Zuhaib Ibrahim, \\ Karim A. Sarhane ${ }^{\#}$
}

Department of Plastic and Reconstructive Surgery, Johns Hopkins University School of Medicine, Baltimore, USA;

${ }^{\#}$ Corresponding Author: karim@jhu.edu

Received 7 August 2013; revised 1 September 2013; accepted 10 September 2013

Copyright (C) 2013 Saami Khalifian et al. This is an open access article distributed under the Creative Commons Attribution License, which permits unrestricted use, distribution, and reproduction in any medium, provided the original work is properly cited.

\begin{abstract}
All allografts suffer a number of unavoidable ischemic insults. These, starting with brain death and ending with reperfusion, are very troublesome, as ischemia-reperfusion injury (IRI) is demonstrated to be a major cause of allograft damage in various types of transplantations. To counter the threat this poses to allograft function, investigators have worked diligently over the past decades in clinical settings and in the laboratory to understand the pathophysiology and immune mechanism underlying IRI hoping to ultimately devise strategies that lessen its detrimental effects on allografts. Herein, we review the major immune components of the IRI dynamic process. Better understanding of the cellular pathophysiological processes underlying IRI will hopefully result in the design of more targeted therapies to prevent the injury, hasten repair, and minimize chronic progressive allograft damage.
\end{abstract}

Keywords: Ischemia-Reperfusion; Reactive Oxygen Species; Allograft Damage; Solid Organ Transplantation; Immune Mechanisms

\section{INTRODUCTION}

During transplantation procedures, allografts are exposed to various periods of complete ischemia; ischemic insults start with brain death and its associated hemodynamic disturbances (elevated intracranial pressure; bradycardia; decreased cardiac output) continue during donor organ procurement, cold preservation, and implantation. Following reperfusion, ischemia-reperfusion injury

"Conflicts of interest: None.
(IRI) is triggered; this could potentially lead to allograft damage (delayed graft function, acute and chronic rejection), posing serious threats to transplant recipients. Along the cascade of pathogenic events that accompany ischemic insults and cause IRI, there has been an appreciation for various immune mechanisms within the allograft itself and their role in priming the allograft for further injury. Free radical-mediated injury releases proinflammatory cytokines and activates the innate immune system ultimately triggering adaptive immune responses and resulting in tissue damage. The outcome of the organ depends on whether cell death or regeneration prevails. The aim of this review is to revisit these immune mechanisms at the cellular and molecular levels, and provide useful clinical recommendations aiming at overcoming the challenges of IRI.

\section{BODY}

\subsection{General Overview of Immune Injury in Ischemic-Reperfusion}

Studies in solid organ transplantation (SOT) have shown that IRI is a potent activator of the immune system, and therefore leads to poor functional outcomes that are directly related to increasing ischemia times [1-4]. Yet ischemia is only one of several factors shown to contribute to acute and chronic rejection, as reperfusion injury further propagates and intensifies the immune response [5]. Specifically, the restoration of blood flow to the previously ischemic allograft compromises the viability of the transplanted tissues via the generation of reactive oxygen species (ROS), activation of the complement system, and the production of pro-inflammatory cytokines that intensify damage in the graft [6]. Furthermore, the expression of MHC antigens is increased after IRI with a concomitant activation of the innate immune system and production of an inflammatory state 
that ultimately leads to acute rejection, increased propensity towards chronic graft deterioration, and decreased potential for tolerance induction and immune regulation [5].

The strong inflammatory response induced by IRI both activates the immune system and mediates tissue injury via activation of leukocytes and endothelial cells, generation of ROS, and upregulation of adhesion molecules and inflammatory cytokines [7]. Cell adhesion molecules on activated leukocytes interact with their ligands on the injured endothelium of the previously ischemic graft, which leads to diapedesis of these cells into the interstitial space. The activated leukocytes also release proteolytic enzymes and generate ROS thereby damaging tissues and propagating the injury response. Notably, the duration of ischemia is directly correlated to the intensity of immune activation, with increased ischemic times corresponding to increased expression of inflammatory cytokines, such as IL-1, IFN- $\gamma$, and TNF- $\alpha$ [7,8]. Ischemia causes further damage to the allograft as oxygenstarved tissues increase glycolysis leading to lactic acid accumulation, which reduces the $\mathrm{pH}$ and impairs membrane transport functions [9]. If perfusion is not restored, the ischemic tissue will undergo necrosis; but on the other hand, reperfusion causes production of ROS in the mitochondria which leads to injury beyond that caused by the ischemia [10].

\subsection{Role of the Innate Immune System}

The activation of the immune system is mediated by endogenous stress signals and a class of primitive proteins expressed by the innate immune system. Specifically, ischemically injured tissues generate damage-associated molecular patterns (DAMPs), which are recognized by pattern-recognition receptors (PRRs) of the innate immune system leading to upregulation of inflammatory cytokines and cell adhesion molecules [11]. This contributes to the recruitment of leukocytes into the graft and, ultimately, to transplant vasculopathy [11,12]. The innate immune system is further triggered by the generation of ROS, which activate heat shock proteins (HSP) that signal toll-like receptors (TLRs) on macrophages and B cells, increasing the propensity towards acute and chronic rejection [13]. Notably, the link between nonspecific injury, such as IRI, and the innate immune system is still speculative, and although there is biological plausibility, unequivocal evidence does not yet exist [14].

\subsection{Role of the Adaptive Immune System}

The adaptive immune system also contributes to the rejection process with the participation of TLRs that sensitize and activate antigen-presenting cells (APCs). The sensitization of APCs leads to a significant increase of effector $\mathrm{T}$ cells that further augments the pro-inflammatory cytokine milieu induced by IRI $[12,15,16]$. An elegant explanation came from Matzinger conducted a series of elegant experiments to investigate the relationship between tissue damage, innate immune responses, and relaying danger signals to the adaptive immune system via TLRs and APCs [17]. These "danger signals" or "alarmins" released during ischemia and reperfusion consist of various graft-derived molecules [DNA, RNA, oxidized proteins and lipids, high-mobility group box-1 (HMGB1), uric acid, and calcium pyrophosphate crystals) [18]. Recent experiments have proven that HMGB1 is actively secreted from at-risk cells via a free-radicalsdependent pathway in the context hepatocyte ischemiareperfusion. This process requires intact TLR4 signaling and calcium-dependent kinases $[19,20]$. In another setting, TLR4 is overexpressed in tubular epithelial cells following IRI. Furthermore, TLR4-/- and MyD88-/(MyD88 being TLR4 signaling pathway protein) mice were protected from IRI kidney dysfunction, with no tubular damage, neutrophil and macrophage accumulation, and expression of proinflammatory cytokines and chemokines [21]. Evidently, TLRs and ROS play a dual immunological role, activating the innate and adaptive immune system, and potentially contributing to both acute and chronic rejection.

\subsection{Role of the Complement Pathway}

Activation of the complement pathway is another critical event leading to tissue injury after IRI. Indeed, complement is considered a key determinant of tissue rejection after SOT as it damages cell membranes through the formation of membrane attack complexes $[6,7,9,22$, 23]. The byproducts of the complement cascade also contribute to tissue rejection, as chemotactic agents such as C5a attract neutrophils to sites of IRI and anaphylatoxins (C3a, C5a) cause degranulation of mast cell and the release of histamine, which further damages tissues.

\subsection{Contribution of the Alloimmune Response}

Although the primary factor leading to transplant rejection is undoubtedly the $\mathrm{T}$ cell alloimmune response triggered by MHC incompatibility, IRI further intensifies this response, and is believed to be the strongest secondary factor to augment graft allogenicity [24,25]. The danger signals produced by ischemic injury induce an elegant interaction of immune activation and signal transduction that predisposes transplanted tissues to immunologic recognition and rejection through upregulation of MHC II (signal 1) and costimulation (signal 2) by activation of APCs [4]. Each episode of acute rejection induces an inflammatory state that is detrimental to 
long-term outcomes of the allograft, as multiple episodes of acute rejection trigger myointimal proliferation, allograft vessel occlusion, and chronic graft deterioration $[4,5,26-29]$. This is particularly true in vascularized composite allotransplantation, where the highly immunogenic skin component is at high risk for multiple episodes of acute rejection, and this has been shown to lead to composite tissue vasculopathy and degeneration in a rat hind limb transplantation model [30]. Therefore, IRI induces an immune response, which propagates further injury, thereby promoting a new injury response and increased immune recognition [31]. This self-perpetuating feature may lead to irreversible tissue damage and chronic rejection. In this regard, further research in novel immunomodulatory protocols aiming at minimizing immunosuppression post transplantation holds great promise, as not only it alleviates the many metabolic (and neoplastic) side effects of high-dose immunosuppression [32] but also seems to offer substantial immune protection from IRI.

\subsection{Direct Implication of Toll-Like Receptors (TLRs)}

A clear relationship between the duration of ischemia and allograft survival has been demonstrated in large clinical trials of SOT, and it is hypothesized that this association is mediated by TLRs that are activated by ROS generated by IRI [5,33]. Ample evidence exists implicating TLRs as key contributors to the rate of acute rejection in heart [34], kidney [21], liver [3], lung [5], skin [35], and islet allografts [36]. In clinical studies of cardiac transplantation, TLR gene expression was found to be associated with endothelial dysfunction and vasculopathy [12]. Notably, Genome-wide association studies (GWAS) have shown that transplant recipients with less responsive TLR genes experience improved immunological outcomes illustrated by fewer rejection episodes and improved graft function [1,2,37]. Noris et al. studied the role of TLR regulation on allograft survival in a fully MHC-mismatched kidney allograft model, and found that absence of a negative regulator of TLRs led to a more vigorous acute rejection response with enhanced IRI and rapid induction of DC maturation [38]. In the same study, induction of transplant tolerance was impaired and the rate of chronic rejection was amplified due to the absence of this negative regulator of TLRs. Similar to the GWAS studies in cardiac transplantation, human kidney allograft recipients with unresponsiveness to their allografts expressed lower levels of MyD88 (a TLR signal adaptor) than their counterparts that experienced chronic rejection, further implicating TLRs as a key determinant in the rejection process [39]. Along these lines, Walker et al was able to demonstrate this link utilizing a fully MHC-mismatched model of skin allo- grafts in MyD88 knockout mice [38]. In this study, MyD88 knockout mice experienced indefinite allograft survival after administration of costimulatory blockade (CTLA4-Ig and anti-CD154), while wild-type animals rejected their allografts at an early timepoint. Similarly, systemic administration of a TLR activator $(\mathrm{CpG})$ successfully militated tolerance induction in skin allografts [40], which together strongly suggests that TLR signaling impairs transplant tolerance [41]. Therefore, if the consequences of IRI can be mitigated, it may be possible to limit or prevent the activation of the immune system that leads to acute and chronic rejection. Novel biomarkers of IRI taking into advantage the ubiquitous involvement of IRI have a great potential in predicting the development and severity of IRI, potentially serving also as prognostic indicators [42].

\subsection{Detrimental and Independent Role of Prolonged Ischemia}

Much information has been gleaned from elucidation of the molecular foundations of IRI, and this has served to inform our understanding of the effects of IRI at the macroscopic level.

In cardiac transplantation, for example IRI commonly occurs in the early post-transplant period, especially with prolonged ischemic time, and is characterized by hyperemia in the previously ischemic myocardium, which later becomes prone to coagulative necrosis [43]. Prolonged ischemia in cardiac tissue promotes increased entry of activated $\mathrm{T}$ cells, leukocyte migration and accumulation in peripheral tissues, as well as binding of natural IgM antibodies to self-antigens exposed after tissue ischemia - a potent activator of the complement cascade $[17,44]$. Consequentially, cardiac transplant recipients subjected to prolonged ischemic times are at increased risk for early graft loss, coronary artery vasculopathy, and early death after transplant [45]. Indeed, large clinical trials have confirmed that prolonged ischemia is an independent risk factor for mortality at 1 and 10 years post-transplantation [45].

In kidney transplants, allografts exposed to prolonged ischemia were prone to more acute rejection episodes in animal models and subsequent clinical trials observed the same effect on human renal transplants [24]. In fact, analysis of more than 6000 kidney transplant recipients revealed that patients with prolonged ischemic times suffered increased early acute rejection episodes and decreased 6-year renal allograft survival-findings that were independent of HLA mismatch, panel reactive antibodies, donor/recipient age, and early rejection treatments [46]. Notably, acute rejection episodes were determined to be a significant risk factor for short and longterm graft survival [47].

In lung and liver allografts, IRI leads to higher inci- 
dences of acute and chronic rejection [5,27]. Although there are very few studies examining IRI in vascularized composite allotransplantation, it is plausible that vascularized composite allografts may be even more susceptible to IRI given the diversity of tissue components contained within the graft [48].

\subsection{Prevention of IRI}

In an era where organ shortage is a universal problem with high rates of death among patients on waiting lists, measures to prevent IRI and ensure healthier allografts and safer transplantation procedures are critical. Kidneys recovered from donors should be stored using pulsatile perfusion, allowing better protection during preservationrelated ischemia, as well as the measurement of several parameters - flow, resistance, lactate excretion, alfa GST - which may be useful to assess the extent of ischemic injury. Prevention of IRI can even be started before organ recovery by donor pretreatment. Pretreatment with antioxidants holds great promise conferring protective effects against liver IRI in a rat and mice models [49,50]. Moreover, the role of hemoxygenase-1 (HO-1, enzyme converting heme into biliverdin, carbon monoxide, and free $\mathrm{Fe}$ ) has been extensively studied in protection from ischemia-reperfusion injury. Exposure of liver transplant recipient animals to inhaled $\mathrm{CO}$ decreased serum alanine transferase, hepatocyte necrosis, and neutrophil infiltrates in dose-dependent fashion [51]. Noteworthy, HO-1 can be induced by simvastatin preconditioning [52]. Interestingly, through its strong anti-inflammatory effect, nicotine has been shown to reduce tubular damage in experimental models of warm ischemia when administered before reperfusion [53]. As for myocardial ischemia-reperfusion injury, it was shown that the use of the bifunctional platelet GPIIIa49-66 ligand confers dosedependent protective effects in a rat model of acute myocardial ischemia [54].

In the human setting, it has been shown that cyclosporine inhibits permeability transition and, when administered on reperfusion, decreases creatine kinase release and infarct size in humans undergoing percutaneous coronary intervention for acute cardiac ischemia [55]. This needs thorough evaluation in transplant models.

Evidently, a greater understanding of the molecular mechanisms underlying protective pathways will pave the way for clinical trials aiming at testing different strategies for minimizing IRI.

\section{CONCLUSION}

IRI is a real threat to the success of transplantation and although some period of ischemia is unavoidable, attempts should be made to minimize it to the greatest extent possible. Clear evidence exists, linking prolonged ischemia to increased episodes of acute and chronic rejection, yet we still do not have a clear understanding of what areas of the immune system can be targeted to mitigate the effects of IRI. Future research trying to bridge this knowledge gap and identify such targets in both the innate and adaptive immune system, as well as characterization of cytokine expression responsible for mediating the effects of IRI may enable longer allograft survival and a better patient quality of life.

\section{ACKNOWLEDGEMENTS}

Publication of this article was funded the Open Access Promotion Fund of the Johns Hopkins University Libraries.

\section{REFERENCES}

[1] Palmer, S.M., Burch, L.H., Davis, R.D., Herczyk, W.F., Howell, D.N., Reinsmoen, N.L. and Schwartz, D.A. (2003) The role of innate immunity in acute allograft rejection after lung transplantation. American Journal of Respiratory and Critical Care Medicine, 168, 628-632. doi:10.1164/rccm.200303-447OC

[2] Krüger, B., Krick, S., Dhillon, N., Lerner, S.M., Ames, S., Bromberg, J.S., Lin, M., Walsh, L., Vella, J., Fischereder, M., Krämer, B.K., Colvin, R.B., Heeger, P.S., Murphy, B.T. and Schröppel, B. (2009) Donor Toll-like receptor 4 contributes to ischemia and reperfusion injury following human kidney transplantation. Proceedings of the $\mathrm{Na}$ tional Academy of Sciences of the United States of America, 106, 3390-3395. doi:10.1073/pnas.0810169106

[3] Zhai, Y., Shen, X., O'Connell, R., Gao, F., Lassman, C., Busuttil, R.W., Cheng, G. and Kupiec-Weglinski, J.W. (2004) Cutting edge: TLR4 activation mediates liver ischemia/reperfusion inflammatory response via IFN regulatory factor 3-dependent MyD88-independent pathway. Journal of Immunology, 173, 7115-7119.

[4] Halloran, P.F., Homik, J., Goes, N., Lui, S.L., Urmson, J., Ramassar, V. and Cockfield, S.M. (1997) The "injury response": A concept linking nonspecific injury, acute rejection, and long-term transplant outcomes. Transplantation Proceedings, 29, 79-81. doi:10.1016/S0041-1345(96)00015-2

[5] Kreisel, D. and Goldstein, D.R. (2013) Innate immunity and organ transplantation: Focus on lung transplantation. Transplant International: Official Journal of the European Society for Organ Transplantation, 26, 2-10. doi:10.1111/j.1432-2277.2012.01549.x

[6] Villamaria, C.Y., Rasmussen, T.E., Spencer, J.R., Patel, S. and Davis, M.R. (2012) Microvascular porcine model for the optimization of vascularized composite tissue transplantation. The Journal of Surgical Research, 178, 452459. doi:10.1016/j.jss.2012.03.051

[7] Shimizu, F., Okamoto, O., Katagiri, K., Fujiwara, S. and Wei, F.-C. (2010) Prolonged ischemia increases severity of rejection in skin flap allotransplantation in rats. Micryosurgery, 30, 132-137.

[8] Kuo, Y.-R., Wang, F.-S., Jeng, S.-F., Huang, H.-C., Wei, 
F.-C. and Yang, K.D. (2004) Nitrosoglutathione modulation of platelet activation and nitric oxide synthase expression in promotion of flap survival after ischemia/reperfusion injury. The Journal of Surgical Research, 119, 92-99. doi:10.1016/j.jss.2003.08.006

[9] Siemionow, M. and Arslan, E. (2004) Ischemia/reperfusion injury: A review in relation to free tissue transfers. Microsurgery, 24, 468-475. doi:10.1002/micr.20060

[10] Wang, W.Z., Baynosa, R.C. and Zamboni, W.A. (2011) Update on ischemia-reperfusion injury for the plastic surgeon: 2011. Plastic and Reconstructive Surgery, 128, 685e-692e. doi:10.1097/PRS.0b013e318230c57b

[11] Akira, S., Uematsu, S. and Takeuchi, O. (2006) Pathogen recognition and innate immunity. Cell, 124, 783-801. doi:10.1016/j.cell.2006.02.015

[12] Methe, H., Zimmer, E., Grimm, C., Nabauer, M. and Koglin, J. (2004) Evidence for a role of toll-like receptor 4 in development of chronic allograft rejection after cardiac transplantation. Transplantation, 78, 1324-1331. doi:10.1097/01.TP.0000137930.40597.03

[13] Akira, S., Takeda, K. and Kaisho, T. (2001) Toll-like receptors: Critical proteins linking innate and acquired immunity. Nature Immunology, 2, 675-680. doi:10.1038/90609

[14] Matzinger, P. (1998) An innate sense of danger. Seminars in Immunology, 10, 399-415. doi:10.1006/smim.1998.0143

[15] Ionita, M.G., Arslan, F., de Kleijn, D.P.V. and Pasterkamp, G. (2010) Endogenous inflammatory molecules engage Toll-like receptors in cardiovascular disease. Journal of Innate Immunity, 2, 307-315. doi:10.1159/000314270

[16] Gill, R.G. (2010) NK cells: Elusive participants in transplantation immunity and tolerance. Current Opinion in Immunology, 22, 649-654. doi:10.1016/j.coi.2010.09.005

[17] Zhang, M. and Carroll, M.C. (2007) Natural antibody mediated innate autoimmune response. Molecular Immunology, 44, 103-110. doi:10.1016/i.molimm.2006.06.022

[18] Wanderer, A.A. (2008) Ischemic-reperfusion syndromes: Biochemical and immunologic rationale for IL-1 targeted therapy. Clinical Immunology, 128, 127-132. doi:10.1016/j.clim.2008.03.514

[19] Klune, J.R., Dhupar, R., Cardinal, J., Billiar, T.R. and Tsung, A. (2008) HMGB1: Endogenous danger signaling. Molecular Medicine, 14, 476-484. doi:10.2119/2008-00034.Klune

[20] Tsung, A., Klune, J.R., Zhang, X., Jeyabalan, G., Cao, Z., Peng, X., Stolz, D.B., Geller, D.A., Rosengart, M.R. and Billiar, T.R. (2007) HMGB1 release induced by liver ischemia involves Toll-like receptor 4 dependent reactive oxygen species production and calcium-mediated signaling. The Journal of Experimental Medicine, 204, 29132923. doi:10.1084/jem.20070247

[21] Wu, H., Chen, G., Wyburn, K.R., Yin, J., Bertolino, P., Eris, J.M., Alexander, S.I., Sharland, A.F. and Chadban, S.J. (2007) TLR4 activation mediates kidney ischemia/ reperfusion injury. The Journal of Clinical Investigation, 117, 2847-2859. doi:10.1172/JCI31008
[22] Reichenbach, D.K., Li, Q., Hoffman, R.A., Williams, A.L., Shlomchik, W.D., Rothstein, D.M., Demetris, A.J. and Lakkis, F.G. (2013) Allograft outcomes in outbred mice. American Journal of Transplantation: Official Journal of the American Society of Transplantation and the American Society of Transplant Surgeons, 13, 580-588. doi:10.1111/ajt.12056

[23] Khalil, A.A., Aziz, F.A. and Hall, J.C. (2006) Reperfusion injury. Plastic and Reconstructive Surgery, 117, 10241033. doi:10.1097/01.prs.0000204766.17127.54

[24] Tullius, S.G., Reutzel-Selke, A., Egermann, F., NieminenKelhä, M., Jonas, S., Bechstein, W.O., Volk, H.D. and Neuhaus, P. (2000) Contribution of prolonged ischemia and donor age to chronic renal allograft dysfunction. Journal of the American Society of Nephrology, 11, 13171324.

[25] Morelli, A.E. and Thomson, A.W. (2007) Tolerogenic dendritic cells and the quest for transplant tolerance. $\mathrm{Na}$ ture Reviews Immunology, 7, 610-621. doi:10.1038/nri2132

[26] Kaufman, C.L., Ouseph, R., Blair, B., Kutz, J.E., Tsai, T.M., Scheker, L.R., Tien, H.Y., Moreno, R., Ozyurekoglu, T., Banegas, R., Murphy, E., Burns, C.B., Zaring, R., Cook, D.F. and Marvin, M.R. (2012) Graft vasculopathy in clinical hand transplantation. American Journal of Transplantation: Official Journal of the American Society of Transplantation and the American Society of Transplant Surgeons, 12, 1004-1016. doi:10.1111/j.1600-6143.2011.03915.x

[27] Hautz, T., Wolfram, D., Grahammer, J., Starzl, R., Krapf, C., Pratschke, J., Lee, W.P.A., Brandacher, G. and Schneeberger, S. (2012) Mechanisms and mediators of inflamemation: Potential models for skin rejection and targeted therapy in vascularized composite allotransplantation. Clinical \& Developmental Immunology, 2012, 757 310 .

[28] Caterson, E.J., Lopez, J., Medina, M., Pomahac, B. and Tullius, S.G. (2013) Ischemia-reperfusion injury in vascularized composite allotransplantation. The Journal of Craniofacial Surgery, 24, 51-56. doi:10.1097/SCS.0b013e31827104e1

[29] Pradka, S.P., Ong, Y.S., Zhang, Y., Davis, S.J., Baccarani, A., Messmer, C., Fields, T.A., Erdmann, D., Klitzman, B. and Levin, L.S. (2009) Increased signs of acute rejection with ischemic time in a rat musculocutaneous allotransplant model. Transplantation Proceedings, 41, 531-536. doi:10.1016/j.transproceed.2009.01.021

[30] Unadkat, J.V., Schneeberger, S., Horibe, E.H., Goldbach, C., Solari, M.G., Washington, K.M., Gorantla, V.S., Cooper, G.M., Thomson, A.W. and Lee, W.P.A. (2010) Composite tissue vasculopathy and degeneration following multiple episodes of acute rejection in reconstructive transplantation. American Journal of Transplantation: Official Journal of the American Society of Transplantation and the American Society of Transplant Surgeons, 10, 251261. doi:10.1111/j.1600-6143.2009.02941.x

[31] Khalifian, S., Cooney, D.S., Lee, W.P.A. and Brandacher, G. (2013) The role of ischemia-reperfusion injury in reconstructive transplantation. Journal of Transplantation Technologies \& Research, S3. 
[32] Sarhane, K.A., Ibrahim, Z., Leto Barone, A.A., Cooney, D.S., Lee, W.P.A. and Brandacher, G. (2012) Minimization of Immunosuppression and Tolerance Induction in Reconstructive Transplantation. Current Surgery Reports, 1, 40-46. doi:10.1007/s40137-012-0008-4

[33] Opelz, G. and Wujciak, T. (1994) The influence of HLA compatibility on graft survival after heart transplantation. The Collaborative Transplant Study. The New England Journal of Medicine, 330, 816-819. doi:10.1056/NEJM199403243301203

[34] Tesar, B.M., Zhang, J., Li, Q. and Goldstein, D.R. (2004) TH1 immune responses to fully MHC mismatched allografts are diminished in the absence of MyD88, a toll-like receptor signal adaptor protein. American Journal of Transplantation: Official Journal of the American Society of Transplantation and the American Society of Transplant Surgeons, 4, 1429-1439. doi:10.1111/j.1600-6143.2004.00544.x

[35] McKay, D., Shigeoka, A., Rubinstein, M., Surh, C. and Sprent, J. (2006) Simultaneous deletion of MyD88 and Trif delays major histocompatibility and minor antigen mismatch allograft rejection. European Journal of Immunology, 36, 1994-2002. doi:10.1002/eji.200636249

[36] Hutton, M.J.H., Westwell-Roper, C., Soukhatcheva, G., Plesner, A., Dutz, J.P. and Verchere, C.B. (2009) Islet allograft rejection is independent of toll-like receptor signaling in mice. Transplantation, 88, 1075-1080. doi:10.1097/TP.0b013e3181bd3fe2

[37] Ducloux, D., Deschamps, M., Yannaraki, M., Ferrand, C., Bamoulid, J., Saas, P., Kazory, A., Chalopin, J.-M. and Tiberghien, P. (2005) Relevance of toll-like receptor-4 polymorphisms in renal transplantation. Kidney International, 67, 2454-2461.

doi:10.1111/j.1523-1755.2005.00354.x

[38] Walker, W.E., Nasr, I.W., Camirand, G., Tesar, B.M., Booth, C.J. and Goldstein, D.R. (2006) Absence of innate MyD88 signaling promotes inducible allograft acceptance. Journal of Immunology, 177, 5307-5316.

[39] Braudeau, C., Ashton-Chess, J., Giral, M., Dugast, E., Louis, S., Pallier, A., Braud, C., Moreau, A., Renaudin, K., Soulillou, J.-P. and Brouard, S. (2008) Contrasted blood and intragraft toll-like receptor $4 \mathrm{mRNA}$ profiles in operational tolerance versus chronic rejection in kidney transplant recipients. Transplantation, 86, 130-136. doi:10.1097/TP.0b013e31817b8dc5

[40] Thornley, T.B., Brehm, M.A., Markees, T.G., Shultz, L.D., Mordes, J.P., Welsh, R.M., Rossini, A.A. and Greiner, D.L. (2006) TLR agonists abrogate costimulation blockade-induced prolongation of skin allografts. Journal of Immunology, 176, 1561-1570.

[41] Chen, L., Wang, T., Zhou, P., Ma, L., Yin, D., Shen, J., Molinero, L., Nozaki, T., Phillips, T., Uematsu, S., Akira, S., Wang, C.-R., Fairchild, R.L., Alegre, M.-L. and Chong, A. (2006) TLR engagement prevents transplantation tolerance. American Journal of Transplantation, 6, 22822291. doi:10.1111/j.1600-6143.2006.01489.x

[42] Sarhane, K. (2012) Tissue CLN3 : A potential biomarker for breast cancer? M.S. Thesis, American University of Beirut, Beirut.
[43] Landin, L., Cavadas, P.C., Garcia-Cosmes, P., Thione, A., Vera-Sempere, F. (2011) Perioperative ischemic injury and fibrotic degeneration of muscle in a forearm allograft: Functional follow-up at 32 months post transplantation. Annals of Plastic Surgery, 66, 202-209. doi:10.1097/SAP.0b013e318206a365

[44] Chalasani, G., Li, Q., Konieczny, B.T., Smith-Diggs, L., Wrobel, B., Dai, Z., Perkins, D.L., Baddoura, F.K. and Lakkis, F.G. (2004) The allograft defines the type of rejection (acute versus chronic) in the face of an established effector immune response. Journal of Immunology, 172, 7813-7820.

[45] Boucek, M.M., Aurora, P., Edwards, L.B., Taylor, D.O., Trulock, E.P., Christie, J., Dobbels, F., Rahmel, A.O., Keck, B.M. and Hertz, M.I. (2007) Registry of the International society for heart and lung transplantation: Tenth official pediatric heart transplantation report-2007. The Journal of Heart and Lung Transplantation, 26, 796-807. doi:10.1016/i.healun.2007.06.006

[46] Salahudeen, A.K., Haider, N. and May, W. (2004) Cold ischemia and the reduced long-term survival of cadaveric renal allografts. Kidney International, 65, 713-718. doi:10.1111/j.1523-1755.2004.00416.x

[47] Ojo, A.O., Wolfe, R.A., Held, P.J., Port, F.K. and Schmouder, R.L. (1997) Delayed graft function: Risk factors and implications for renal allograft survival. Transplantation, 63, 968-974. doi:10.1097/00007890-199704150-00011

[48] Lee, W.P., Yaremchuk, M.J., Pan, Y.C., Randolph, M.A., Tan, C.M. and Weiland, A.J. (1991) Relative antigenicity of components of a vascularized limb allograft. Plastic and Reconstructive Surgery, 87, 401-411. doi:10.1097/00006534-199103000-00001

[49] Ben Mosbah, I., Mouchel, Y., Pajaud, J., Ribault, C., Lucas, C., Laurent, A., Boudjema, K., Morel, F., Corlu, A. and Compagnon, P. (2012) Pretreatment with mangafodipir improves liver graft tolerance to ischemia/reperfusion injury in rat. PloS One, 7, e50235. doi:10.1371/journal.pone.0050235

[50] Coriat, R., Leconte, M., Kavian, N., Bedda, S., Nicco, C., Chereau, C., Goulvestre, C., Weill, B., Laurent, A. and Batteux, F. (2011) Mangafodipir protects against hepatic ischemia-reperfusion injury in mice. PloS One, 6, e27005. doi:10.1371/journal.pone.0027005

[51] Kaizu, T., Ikeda, A., Nakao, A., Tsung, A., Toyokawa, H., Ueki, S., Geller, D.A. and Murase, N. (2008) Protection of transplant-induced hepatic ischemia/reperfusion injury with carbon monoxide via MEK/ERK1/2 pathway downregulation. American Journal of Physiology. Gastrointestinal and Liver Physiology, 294, G236-G244. doi:10.1152/ajpgi.00144.2007

[52] Lai, I.-R., Chang, K.-J., Tsai, H.-W. and Chen, C.-F. (2008) Pharmacological preconditioning with simvastatin protects liver from ischemia-reperfusion injury by heme oxygenase-1 induction. Transplantation, 85, 732-738. doi:10.1097/TP.0b013e3181664e70

[53] Sadis, C., Teske, G., Stokman, G., Kubjak, C., Claessen, N., Moore, F., Loi, P., Diallo, B., Barvais, L., Goldman, M., Florquin, S. and Le Moine, A. (2007) Nicotine pro- 
tects kidney from renal ischemia/reperfusion injury through the cholinergic anti-inflammatory pathway. PloS One, 2, e469. doi:10.1371/journal.pone.0000469

[54] Fan, J., Jing, F., Dang, S. and Zhang, W. (2013) Protective effects of bifunctional platelet GPIIIa49-66 ligand on myocardial ischemia-reperfusion injury in rats. Open Journal of Immunology, 5, 15-20.

[55] Piot, C., Croisille, P., Staat, P., Thibault, H., Rioufol, G.,
Mewton, N., Elbelghiti, R., Cung, T.T., Bonnefoy, E., Angoulvant, D., Macia, C., Raczka, F., Sportouch, C. Gahide, G., Finet, G., André-Fouët, X., Revel, D., Kirkorian, G., Monassier, J.-P., Derumeaux, G. and Ovize, M. (2008) Effect of cyclosporine on reperfusion injury in acute myocardial infarction. The New England Journal of Medicine, 359, 473-481. doi:10.1056/NEJMoa071142 